There are too few data to permit of establishing the values of the constant $k$ for concentrations greater than five mols. Still since the values of the " $k$ 's" increase by about 0.08 as the concentration increases by one mol., if it be legitimate to assume that this regularity continues, similar formulas may readily be found for greater concentrations.

\title{
ESTIMATION OF THE LIME, POTASH, AND PHOSPHORIC ACID IN HAWAIIAN SOILS PROBABLY AVAIL- ABLE FOR THE IMMEDIATE CROP.
}

\author{
By Walter Maxwell. \\ Received January II, 1899. \\ ASPARTIC ACID METHOD.
}

I. The hypothetic principle of this method rests upon the assumption that the solvents used shall compare with the solvents that operate in the processes of soil disintegration, and plantfood preparation, in the field.'

2. The standards of control of this method are the ascertained results of the natural processes of soil decomposition in the field, under the conditions of climate and nature of the soils of the Hawaiian Islands, as indicated by the "results of cropping" and "the composition of the waters of discharge" flowing from the land into the sea."

3. The sample is obtained by the mode given in previous publications; viz., by the pipe, where this is practicable, otherwise by the spade. The calculation of available matter per acre is based upon the specific gravity (weight of the cubic foot) of the soil, and the depth to which the sample is taken. In thin soils the amount is less, in deep soils greater, than the amount found in one acre to a depth of one foot, upon which depth, calculations, so far, in the use of this method, have been based.

4. The solvent used in this method is aspartic acid. This acid was adopted because it was found that "aspartic acid dissolves phosphoric acid, lime, potash, and other bases (iron and alumina) out of the soil in almost the exact proportions that these ele-

1 see the author's work on the "I,avas and Soils of the Hawailan Islands ;" also this Journal, 20, $107(1898)$.

2See "Lavas and Soils of the Hawaiian Islands." 
ments have been found in the 'waters of discharge,' and in which they are being removed by "cropping." "'

5. The method established and used so far, but which the author may modify in some features, is as follows: 200 grams of whole soil (not fine earth), air-dried, was put into a glassstoppered Winchester quart bottle; to this soil was added I, cc. of distilled water containing ten grams of pure aspartic acid, thus making a one per cent. solution. The bottle was gently shaken every fifteen minutes during the day portion of twentyfour hours (from eight o'clock A.M. to five o'clock P.M.). By "gently shaken" is meant that the bottle was taken up, and shaken in circular movement until the soil at the bottom was totally and thoroughly moved, but without ever rising above the surface of the solution, thus avoiding a remnant of the soil attaching to the sides of the bottle above the solution surface. This explanation is given because it has been shown that in "shaking the bottle containing the soil and solvent, which is the only mode of securing a uniform distribution and action of the solvent, the results of the action will be in large measure proportionate to the mode and vigor of the shaking." At the end of twenty-four hours the contents of the bottle were emptied upon a filter, when $750 \mathrm{cc}$. of the clear filtrate were taken for analysis. The $750 \mathrm{cc}$. of filtrate was evaporated to dryness, and the residue gently ignited to remove all organic matter. The mineral residue was moistened with hydrochloric acid, evaporated and dried; then again softened with the same acid, warmed, and taken up with water, and filtered. After removal of iron and alumina from the filtrate with ammonium, the lime and potash were estimated in the usual way. The ammonia precipitate, containing also the iron and alumina, was dissolved in a little hydrochloric acid, neutralized with ammonia, the solution cleared with a little nitric acid, after which the phosphoric acid was precipitated and estimated by the common practice.

6. The estimation of the amounts of the elements that ate "probably available for the immediate crop" is drawn from the foregoing analysis: As "a one per cent. solution of aspartic acid takes out of Hawaiian soils in twenty-four hours the same amounts of lime, potash, and phosphoric acid that are remored

1 See "Lavas and Soils of the Hawairan Islands," pp. ry-rB.

2 Ibid, pp. 136-13s. 
during the production of ten crops of cane, therefore one-tenth of these amounts may be taken as a nearest approach to the proportions of lime, potash, and phosphoric acid that are available for the immediate crop."

As it has been said, the principle of this method rests upon the assumption that the solvent used shall compare with the solvents that are actually operating in nature; and that the standards of control of the results of this method are the ascertained results of the natural processes of soil-decomposition in the field. Not any consideration has made it appear advisable to the author that a solvent should be used which is not found among the acids that resuit from vegetable existence and decay, and which consequently is not used by nature in the field. It has, on the other hand, appeared to him absolutely necessary that, before concluding that the results obtained by the use of any artificial method of examination are rational, and of any authority and value, these results should be subjected, if possible, to comparison with the standard of results actually following from the processes operating in the field.

HAWAIIAN EXPERIMENT STATION.

[CONTRIBUtions FROM THE HaveMEYER LABORATORIES, COLUMBIA UNiVERSITY, NO. 5.1

\section{TESTS FOR BORIC ACID.}

BY VICTOR LENHER AND J, S. C. WELLS.

Received January 12,889

THE following investigation of the various tests for boric acid originated in an attempt to improve on the wellknown boric ether or flame test.

In Newth's "Chemical Lecture Experiments," p. 227 ( $I 892$ ), is pictured and described an apparatus for producing this gas on a comparatively large scale. It occurred to us that this might be so modified as to make it useful as a qualitative test, and we devised the apparatus shown in the cut. It consists of a testtube (six inches), fitted with a cork through which a glass-tube passes, the latter being drawn out so as to form a moderatesized jet. In the test-tube is placed a mixture of the borate, conceutrated sulphuric acid and alcohol, and the cork and jet

1 See "Lavas and Solls of the Hawailan Islands," p. I8I. 